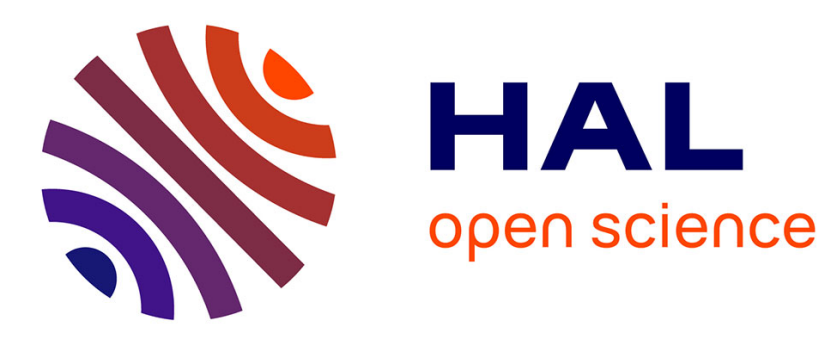

\title{
Impact of tool wear on cross wedge rolling process stability and on product quality
}

Catalina Gutierrez, Laurent Langlois, Cyrille Baudouin, Régis Bigot, Eric

Fremeaux

\section{- To cite this version:}

Catalina Gutierrez, Laurent Langlois, Cyrille Baudouin, Régis Bigot, Eric Fremeaux. Impact of tool wear on cross wedge rolling process stability and on product quality. ESAFORM Conference on Material Forming, Apr 2017, Dublin, Ireland. pp.190008-1-190008-6, 10.1063/1.5008221 . hal02295669

\section{HAL Id: hal-02295669 \\ https://hal.science/hal-02295669}

Submitted on 24 Sep 2019

HAL is a multi-disciplinary open access archive for the deposit and dissemination of scientific research documents, whether they are published or not. The documents may come from teaching and research institutions in France or abroad, or from public or private research centers.
L'archive ouverte pluridisciplinaire HAL, est destinée au dépôt et à la diffusion de documents scientifiques de niveau recherche, publiés ou non, émanant des établissements d'enseignement et de recherche français ou étrangers, des laboratoires publics ou privés. 


\title{
Impact of Tool Wear on Cross Wedge Rolling Process Stability and on Product Quality
}

\author{
Catalina GUTIERREZ ${ }^{1, \text { a) }}$ Laurent LANGLOIS $^{1, \text { b) }}$ Cyrille BAUDOUIN $^{1, c)}$ Régis $^{1}$ \\ BIGOT $^{1, d)}$ Eric FREMEAUX ${ }^{2, \text { e) }}$
}

\author{
${ }^{1}$ Arts et Métiers ParisTech - Laboratoire LCFC, 4 rue Augustin Fresnel, 57078, Metz, France. \\ ${ }^{2}$ Ateliers des Janves, Avenue des Marguerites, 08120, Bogny-sur-Meuse, France \\ a) catalina.gutierrez@ensam.eu \\ b) laurent.langlois@ensam.eu \\ c) cyrille.baudouin@ensam.eu \\ d) regis.bigot@ensam.eu \\ e) eric.fremeaux@ateliers-janves.fr
}

\begin{abstract}
Cross wedge rolling (CWR) is a metal forming process used in the automotive industry. One of its applications is in the manufacturing process of connecting rods. CWR transforms a cylindrical billet into a complex axisymmetrical shape with an accurate distribution of material. This preform is forged into shape in a forging die. In order to improve CWR tool lifecycle and product quality it is essential to understand tool wear evolution and the physical phenomena that change on the CWR process due to the resulting geometry of the tool when undergoing tool wear. In order to understand CWR tool wear behavior, numerical simulations are necessary. Nevertheless, if the simulations are performed with the CAD geometry of the tool, results are limited. To solve this difficulty, two numerical simulations with FORGE® were performed using the real geometry of the tools (both up and lower roll) at two different states: (1) before starting lifecycle and (2) end of lifecycle. The tools were 3D measured with ATOS triple scan by GOM ${ }^{\circledR}$ using optical 3D measuring techniques. The result was a high-resolution point cloud of the entire geometry of the tool. Each 3D point cloud was digitalized and converted into a STL format. The geometry of the tools in a STL format was input for the 3D simulations. Both simulations were compared. Defects of products obtained in simulation were compared to main defects of products found industrially. Two main defects are: (a) surface defects on the preform that are not fixed in the die forging operation; and (b) Preform bent (no longer straight), with two possible impacts: on the one hand that the robot cannot grab it to take it to the forging stage; on the other hand, an unfilled section in the forging operation.
\end{abstract}

\section{INTRODUCTION}

Cross wedge rolling (CWR) is a metal forming process used in the automotive industry. One of its applications is in the manufacturing process of connecting rods where CWR is utilized as a preforming operation before the hot forging stages. CWR transforms a cylindrical billet into a complex axisymmetrical shape with an accurate distribution of material. In the CWR process, this rolled part can have either one simple or multiple diameter reductions. The CWR tools consist of one or several wedges, the number of wedges equaling the number of reductions of the rolled part. In the industrial case presented in this study, the rolled part is symmetric and has five diameter reductions as it is shown in Fig. 1a. This rolled part is forged into shape in a forging die (see Fig. 1b), the part transfer between the CWR mill and the forging machine being robotized. As the rolled part is not the final product, it is referred in this article as a preform. Two main configurations of CWR are used under industrial conditions: (a) flat-type and (b) two roll-type. The latter is used in the industrial case of the present study (see Fig. 1c). 


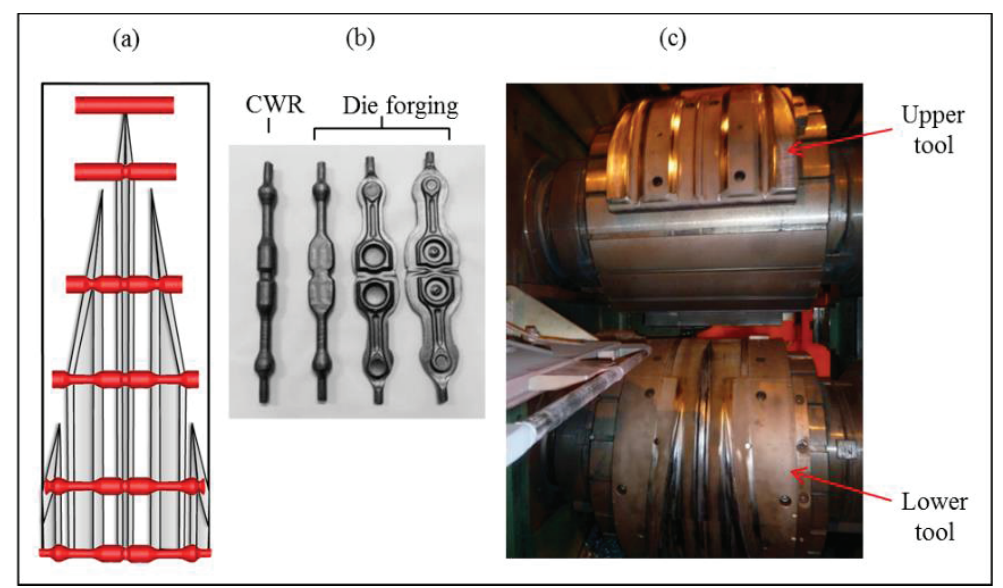

FIGURE 1. (a) CWR process (b) Connecting rods manufacturing route and (c) CWR two-roll configuration

Comprehension of the CWR process is still in developing stages. Results in literature are limited because first, in some cases research has been only theoretical [1]. Second, few researches have studied the CWR process in multi wedge conditions. In fact, mostly all of the results available in literature concern a single wedge CWR process [2]. The main fields of research of the CWR process have been: the stability of the process [3], the optimization of the main parameters of the wedge [4] and the main defects of the rolled products [5]. Comprehension of the CWR tool lifecycle is still limited. [6] studied the influence of cooling conditions of CWR tools on tool wear in order to improve tool life. [2] studied numerically the influence of tool parameters on tool wear depth. Their work focuses on how the main angles of the tool (spreading and forming angles) evolve throughout the lifecycle and what are the optimum values for these geometrical parameters in order to improve tool lifecycle.

Nevertheless, the available research focuses mainly on how the tools wear out but it doesn't study the influence of tool wear on the rolled parts. Additionally, the quality criteria of rolled parts only consider the intrinsic defects of CWR products like necking, spiral grooves or internal cavities. There is not available research that studies the defects of rolled products due to tool wear. Defects that technically don't affect the quality of the preform itself, but affect the quality of the final product, after the forging stages.

This paper proposes to study the sensibility of a CWR numerical model to CWR tool wear. A methodology is developed in order to verify if the same defects due to tool wear, of real rolled parts obtained industrially, can be obtained in simulation. The methodology is described as follows. First, the industrial CWR process was studied in order to identify the intrinsic defects of the rolled parts and the other defects due to tool wear that aren't corrected in the forging stage. Then, in order to analyze wear, the tools (both up and lower roll) were 3D scanned at two different states: before starting lifecycle (unused tools) and after lifecycle (worn tools). In the first analysis both scans were compared to each other in order to identify the worn zones of the tool. Later, the impact of the tool wear was verified by comparing two numerical simulations of the process involving the 3D scanned geometries of the tool. The geometries of the rolled part obtained by both simulations were compared to that of real parts rolled under industrial conditions. A first validation of the numerical simulation and its sensitivity to tool wear can be considered as achieved if the defects identified on the industrially rolled parts are reproduced by the simulation with the worn geometry and not with the unused one.

\section{INDUSTRIAL CONDITIONS}

Today, in the present study, CWR tools can produce up to few 100000 preforms in a lifecycle. There are some surface defects on the CWR preform, such as spiral grooves, that appear throughout the entire lifecycle of tools. This surface defect is mainly fixed at the forging stage, therefore it doesn't have an impact on the final product. When the tools start to wear out, only the quality of the preform is affected because the defects are also fixed in the forging stage. However, with time, the quality of the connecting rod is affected as well. Two main defects of CWR preforms due to tool wear that affect the final product are (see Fig. 2): 
- The surface defects on the preform are not fixed in the die forging operation. This defect is difficult to characterize because it doesn't have a regular form. It appears like a circular groove located at the end of the central reduction and the beginning and the end of the second reduction. Its depth is about 0,1 to $0,3 \mathrm{~mm}$.

- The preform is bent (no longer straight) with two possible impacts: first, the robot cannot grab the preform to the forging stage; or, second, the forging dies are not fulfilled. CWR tool change is considered necessary when the reject rate of the final product is too high.

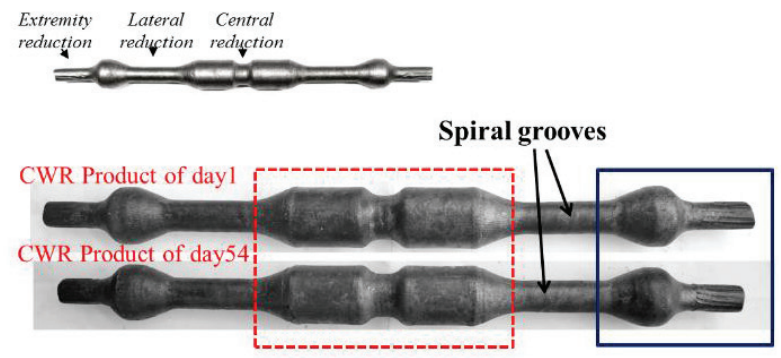

(a)

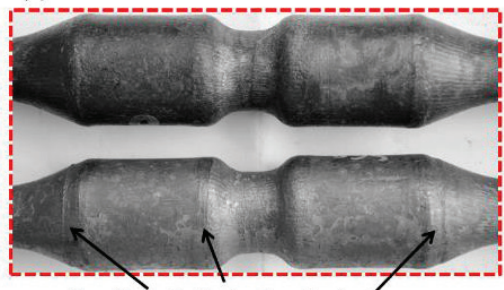

Surface defects due to tool wear (b)

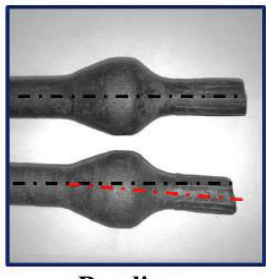

Bending

FIGURE 2. Effects of tool wear on CWR preforms

\section{SCAN 3D OF THE CWR TOOLS REAL GEOMETRY}

To perform the 3D simulations with the real geometry of the tools it is necessary, first, to measure and digitalize the geometry of the tools, and second, to save the data describing the layout of the 3D geometry into an STL format. To solve the first point, the tools were 3D measured with ATOS triple scan by GOM ${ }^{\circledR}$ using optical 3D measuring techniques as shown in Fig. 3a. The result is a high-resolution point cloud of the entire geometry of the tool (see Fig. $3 b$ ). To solve the second difficulty, each 3D point cloud was digitalized and converted into a STL format using the GOM Inspect ${ }^{\circledR}$ software.

The wear zones of the tool can be seen in Fig. 3c. This is possible by making a surface comparison between the new tool and the worn tool. Before describing the wear zones, it is important to describe the main functional zones of the wedge. First, there is the knifing zone where the billet's diameter is reduced to the demanded depth reduction. Following, we have the forming zone where the billet is plastically deformed, being forced to flow to through its longitudinal axis. The final zone is the sizing zone, where cross-section ovalization and undesired axial twist of the billet are removed. Regarding wear zones, the analysis show the following. The wedge of the central reduction is the one with fewer zones of wear, mainly at the knifing zone. The remaining wedges have important wear zones both at the knifing and forming zones. We can identify a decrease in the height of the wedge and an important loss of material at the active facets of the wedge. The maximum wear zones are at the forming zone with a loss of material up to $1 \mathrm{~mm}$.

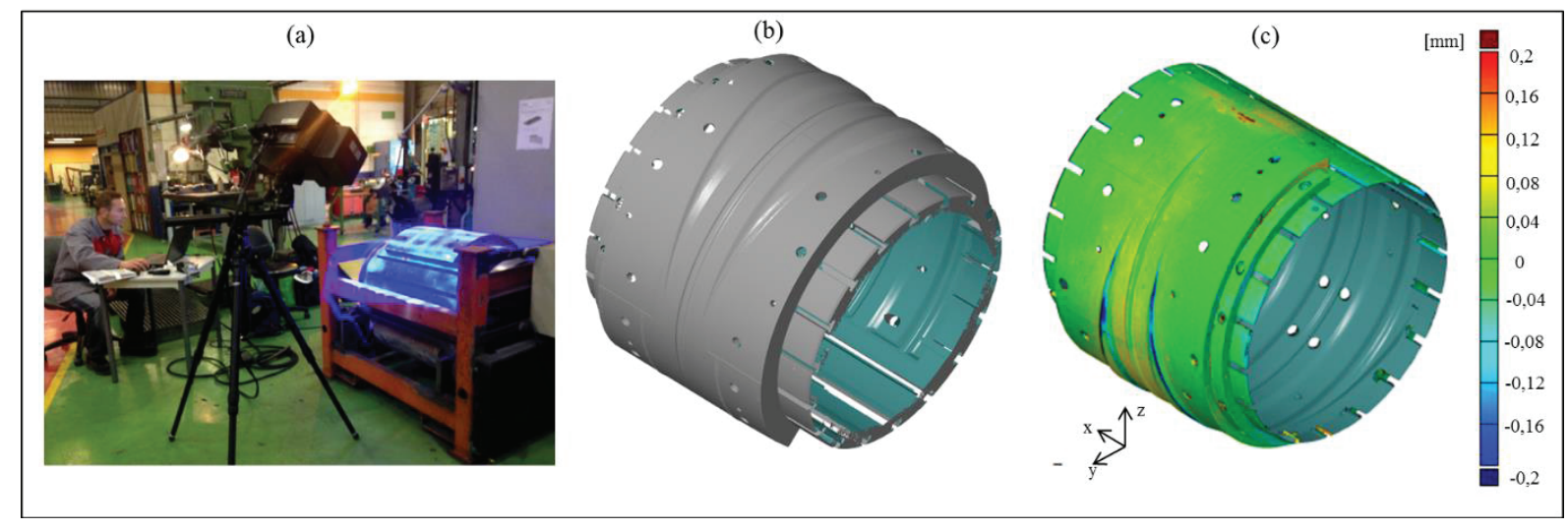

FIGURE 3. (a) 3D non-contact measurement of CWR tools and (b) 3D point cloud digitalization of CWR tool and (c) Unused tool and worn tool comparison. Wear zones of the CWR tool 


\section{DESCRIPTION OF THE FEM MODEL}

The simulations were performed with the commercial FEM software Forge ${ }^{\circledR}$. The model of the $3 \mathrm{D}$ simulation is shown in Fig. 4. Seeking for computational stability, only half a billet is rolled under the hypothesis of process symmetry. For both simulations, the diameter of the billet is about $40 \mathrm{~mm}$ for a length of about $150 \mathrm{~mm}$. The material's rheological model based on Hansel Spittel law was obtained from the material database of FORGE. The initial temperature is $1250^{\circ} \mathrm{C}$. The material is considered isotropic and the yielding behavior follows the Von Mises yield criterion. The upper and lower tools were positioned so as to obtain the desired rolled part. This means defining the spacing between both tools, in other words defining the rotational axis. Tools were considered rigid. The initial temperature was set at $200^{\circ} \mathrm{C}$.

Heat transfer phenomena with the surrounding environment can occur in the form of conduction-convection, radiation and constant transfer. Regarding the tool-billet interface, a constant heat transfer coefficient is defined. The work rate dissipated by friction is also taken into account; consequently the effusivity of the tool is also defined. Regarding the billet-air interaction, one must define the coefficient of global transfer between the external environment and the material, the temperature of the surrounding environment (for this case it is set up to $30^{\circ} \mathrm{C}$ ) and the material's emissivity.

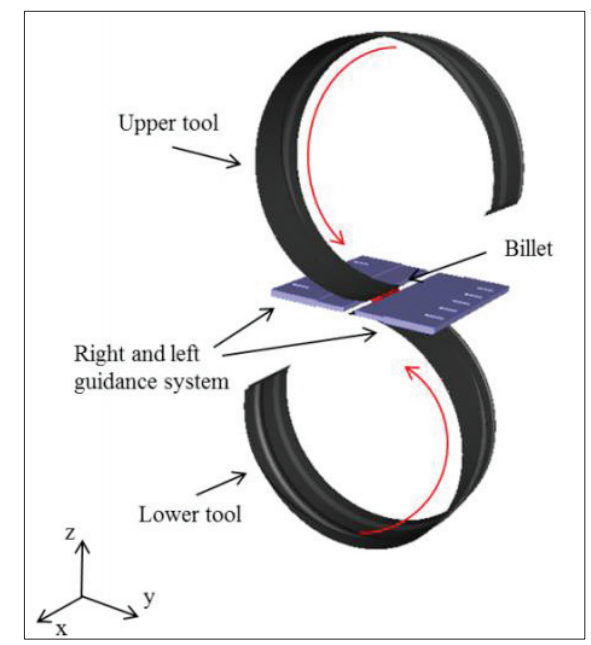

FIGURE 4. Model of the 3D simulation of CWR

The viscoplastic friction law in equation (1) is chosen, where $\alpha_{\mathrm{f}}$ is the friction factor, Pf is the sensitivity to slipping velocity, $\mathrm{K}_{\mathrm{f}}$ the consistency of the billet material and $\mathrm{v}_{\mathrm{g}}$ is the slipping velocity.

$$
\tau(v)=-\alpha_{f} * K_{f} *\left\|\Delta v_{g}\right\|^{P f^{-1}} * \Delta v_{g}
$$

\section{RESULTS AND DISCUSSIONS}

The rolled parts obtained in both simulations are presented in Fig. 5, where (a) is the rolled part obtained with new tools and (b) is the rolled part obtained with worn tools.

For the first case (unused tools), the rolled part is in overall agreement with the dimensions of the real rolled parts. A maximum error of $7 \%$ is found at the diameter of the lateral reduction. Spiral grooves are observed in the lateral reduction, as it is found industrially. The rolled part however, has a higher bending defect compared to industrial results. In the numerical simulation, the bending defect is produced at the end of the extremity reduction formation at $2,5 \mathrm{~s}$. On the other hand, for the second case (worn tools), the rolled part wasn't entirely formed. In fact, during the first two reductions the rolled part was formed, until about 2,3s during the formation of the extremity reduction that a slipping problem occurred. To explain the slipping phenomenon, a description of the formation of the extremity reduction needs to be explained. During the forming of the extremity reduction, the billet forms a tulip as shown in 
Fig. 6. When the tulip is closed, an internal cavity is formed. This tulip is more or less important, depending on the volume of material remaining to form the extremity reduction, and so are the forces counteracting the rotation of the billet.

(a) Rolled part (unused tools)

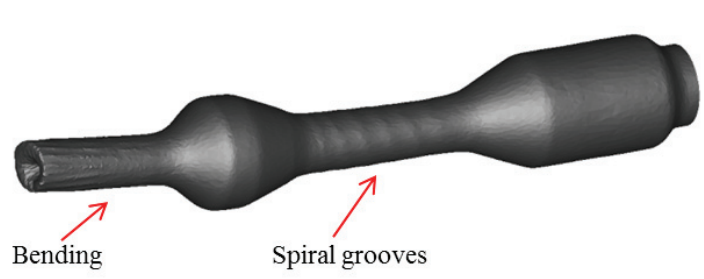

(b) Rolled part (worn tools)

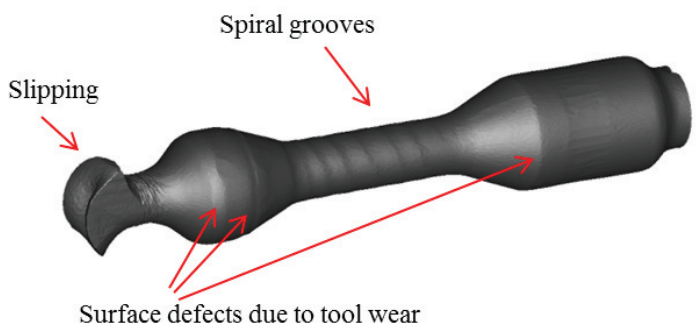

FIGURE 5. Rolled parts obtained in simulation (a) with new tools and (b) with tools at the end of lifecycle

When comparing the remaining volume of material of both simulations, it was seen that the remaining material is less in the case of worn tools as seen in see Fig. 6. This is in agreement with the first analysis of tool wear. The decrease of the height of the wedges has an impact on the material distribution of the billet; less material is left to form the extremity reduction. Like in the numerical simulation, the industrial observations show that the formation of the extremity reduction is a source of instabilities of the rolling cycles. Nevertheless, in reality the slipping phenomenon occurs, but the rolled part is ultimately formed with a bending defect.
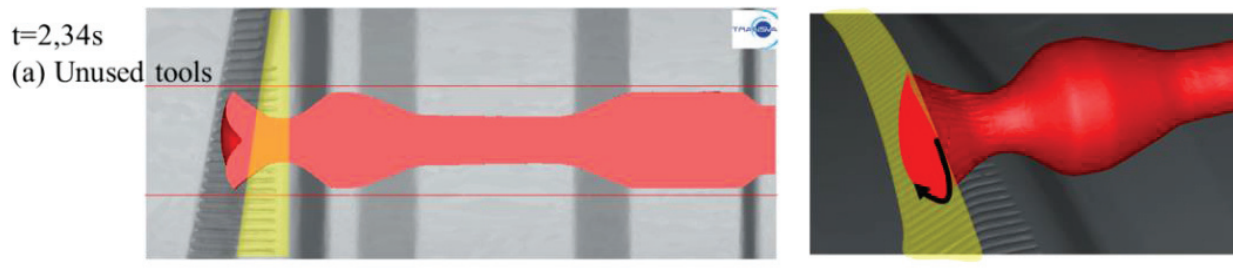

(b) Worn tools
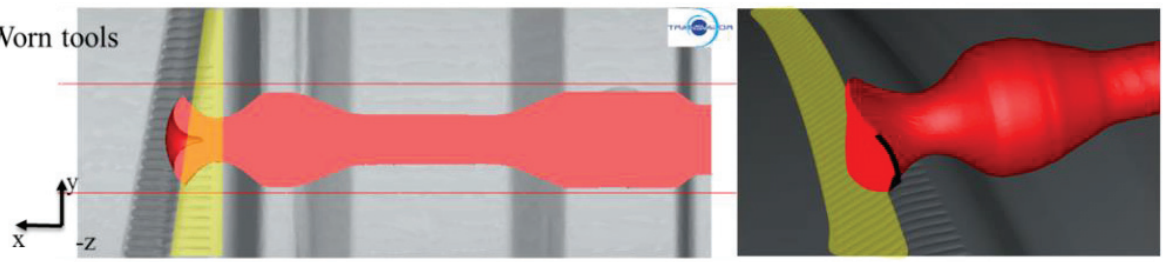

FIGURE 6. Remaining volume to form the extremity reduction (a) unused tools and (b) worn tools

The analysis made regarding the mechanical behavior, up to the beginning of slipping for worn tools $(2,3 \mathrm{~s})$, showed no significant difference. Spiral grooves are also observed in the lateral reduction of the rolled part of worn tools. As the rolled part wasn't entirely formed, the bending defect was difficult to analyze. In Fig. 7a, it is also possible to see a necking phenomenon more important for case (a) unused tools. This difference is again related with the material distribution of the billet. For case (b) worn tools, as the height of the lateral wedge is decreased due to tool wear, the diameter of the lateral reduction is bigger and so the reduction ratio is lower. The necking phenomenon is also observed industrially with the same tendency. The necking phenomenon decreases with the course of tool lifecycle. Nevertheless, the phenomenon is amplified in simulation as it is shown in Fig. 7b. 
(a) Rolled parts geometry at $\mathrm{t}=2,34 \mathrm{~s}$ (Before slipping)

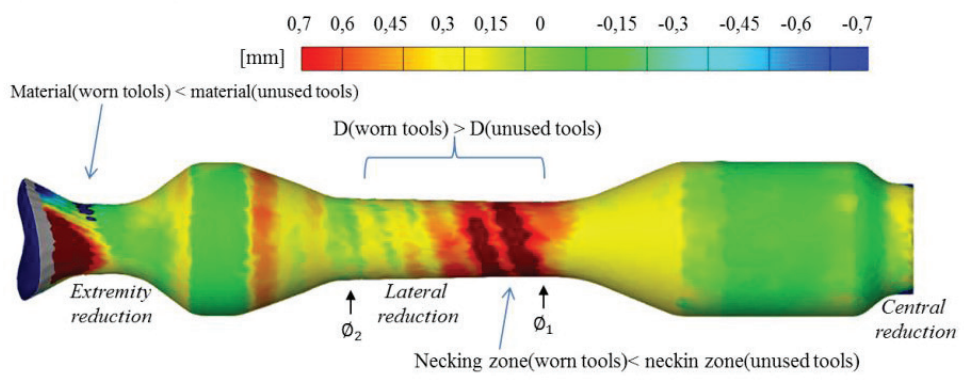

(b) Necking phenomenon analysis found industrially and in simulation

\begin{tabular}{|c|c|c|c|}
\hline \multicolumn{4}{|c|}{$\left(\emptyset_{2}-\emptyset_{1}\right)[\mathrm{mm}]$} \\
\hline \multicolumn{2}{|c|}{ Unused tools } & \multicolumn{2}{c|}{ Worn tools } \\
\hline Real & Num. & Real & Num. \\
\hline 0,8 & 1,3 & 0,3 & 0,7 \\
\hline
\end{tabular}

FIGURE 7. Rolled parts comparison at $\mathrm{t}=2,34 \mathrm{~s}$ (before slipping)

\section{CONCLUSIONS}

This paper presents a methodology for a better understanding of CWR tool wear impact on products by using 3D scans of tools at the beginning of lifecycle and end of lifecycle. Identifying and characterizing wear zones is possible by comparing the 3D scans to each other. The wear analysis showed a decrease on the height as well as an important loss of material of the active forming facets of the lateral and extremity wedges. The results in the numerical simulations showed that this evolution of the geometry of the CWR tool seems to have an impact on the distribution of the billet's material during the rolling cycle. Higher quantity of material stays in the lateral reduction, while fewer quantity of material remains for the formation of the extremity reduction. The size of the tulip, which is formed during the extremity reduction, affects the forces counteracting the rotation of the billet producing instabilities such as slipping or bending. The distribution of material of the billet appears also to have an impact on the necking phenomenon that is actually reduced with worn tools. This same tendency is observed industrially. The surface defects are observed in the same areas of the real products and are only seen in the case of worn tools.

A key parameter for the stability of CWR process and the numerical simulation is the billet/tool interface. Industrially, this evolves over the lifecycle of the tools; in simulation however, this evolution of the friction parameters is not taken into account. In future studies, a parametric study can be performed to adequate the friction parameters appropriate for each case: unused tools and worn tools. To validate the friction parameters, a comparison can be made between the rolling torques measured industrially at the beginning of lifecycle and at the end of lifecycle, and the rolling torques obtained in both simulations.

For a better understanding of the stability of the CWR process due to variations on the quantity of material left to form the extremity reduction, experimental tests can be performed with billets of different lengths. For a same tool geometry and same spacing between the tools, the volume differences between the billets should allow the understanding of the extremity reduction formation. Analysis can be made regarding the amplitude of the rolling torque and of the bending defect. Results can indicate actions to be taken during the lifecycle of CWR tools, such as reducing the spacing of the tools to respect the distribution of material initially planned for new tools.

\section{REFERENCES}

1. G. Fang, LP. Lei \& P. Zeng, Three-dimensional rigid- plastic finite element simulation for the two-roll crosswedge rolling process (Journal of Materials Processing Technology 2002) pp. 245-249

2. Jie Zhou, Chuan Xiao, Yingyan Yu \& Zhi Jia, Influence of tool parameters on tool wear in two-roll cross-wedge rolling (International Journal of Advanced Manufacturing Technology 2012)

3. M. Hayama, Optimum working conditions in the cross rolling of stepped shaft (Journal of Mechanical Working Technology 1979) pp. 31-46.

4. Z. Pater \& W. Weronski, Selection of geometric parameters of transverse wedge rolling tools (Journal of Materials Processing Technology 1992) pp. 273-280.

5. Li \& Lovell, Cross wedge rolling failure mechanisms and industrial application (International Journal of Advanced Manufacturing Technology 2008) pp. 265-278.

6. Menghan Wang, Dong Xiang, Chuan Xiao \& Jie Zhou, Influence of cooling conditions of tools on central deformation of workpiece and tool wear in cross wedge rolling (International Journal of Advanced Manufacturing Technology 2011) 